\title{
Maternal nutrition in early pregnancy
}

\author{
BY R. W. SMITHELLS, CAROL ANKERS, \\ MARGARET E. CARVER, DOROTHY LENNON, C. J. SCHORAH \\ AND SHEILA SHEPPARD \\ Department of Paediatrics and Child Health, University of Leeds, \\ 27 Blundell Street, Leeds LS1 3ET
}

\section{(Received 26 January 1977 - Accepted 21 March 1977)}

\begin{abstract}
1. Mean daily nutrient intakes of 195 women in the first trimester of pregnancy were assessed by weighed dietary records.

2. In comparison with recommended intakes for non-pregnant women aged 18-55 years (Department of Health and Social Security, 1969), more than two-thirds of the subjects were having insufficient energy, iron and cholecalciferol. Unsatisfactory intakes of other nutrients were not uncommon. In relation to recommended intakes for the second trimester (Department of Health and Social Security, 1969), all mothers were having insufficient cholecalciferol and more than $80 \%$ of mothers had unsatisfactory intakes of energy and Fe.

3. Intakes appreciably lower than those recommended were associated with the following factors: social classes III, IV and V; maternal age under 20 years; smoking ten or more cigarettes daily; vomiting on more than $3 \mathrm{~d} /$ week.
\end{abstract}

The reproductive performance of mothers from social classes IV and V is less successful than that of mothers from social classes I and II when judged by perinatal mortality rates, mean birth weight or the frequency of major maternal or fetal complications (Butler \& Bonham, 1963; Butler \& Alberman, 1969). It is widely believed that nutritional differences might account for some of the variation in reproductive capability.

In 1969, we began a study to determine whether maternal nutrition in early pregnancy could be related to the outcome of the pregnancy. The emphasis of the biochemical aspects of the study has been on vitamin nutrition rather than on energy or protein nutrition (Smithells, Sheppard \& Schorah, 1976), but the early stages of the programme included a dietary survey of approximately 200 women in the first trimester, this being the most important period of pregnancy as far as miscarriages and congenital malformations are concerned.

Pregnant women in the first trimester and resident in the City of Leeds were recruited for the main study through their family doctors or hospital antenatal clinics. The sample was therefore partly self-selected but the social class distribution was comparable to that of the general population (Office of Population Cerisuses and Surveys, 1973). Participants were interviewed by a doctor, and a questionnaire was completed which included the occupation of husband and wife (for determination of social class according to Office of Population Censuses and Surveys, 1970) and the mother's previous and present smoking habits. A blood sample was taken for biochemical analysis and mothers volunteering to enter the dietary survey were interviewed by a dietitian. Initially, only primigravidae were admitted to the diet study but later multigravidae were included.

\section{MATERIAL}

Completed records which were accepted for analysis were obtained from 195 mothers. A further four records were discarded, three of these because the participants had failed to maintain adequate records despite close supervision, and one record was discarded 
Table 1. Relative no. (\% total) of 195 women in the first trimester of pregnancy having mean daily nutrient intakes below those recommended by the Department of Health and Social Security (1969) for moderately-active non-pregnant women aged 18-55 (RDI $\left.I_{N P}\right)$ and for women in the second trimester of pregnancy $\left(R D I_{P 2}\right)$

\begin{tabular}{lrcrrr}
\multicolumn{1}{c}{$\quad r$ Nutrient } & No. & $\%$ Total & No. & $\%$ Total \\
Energy & 141 & 72 & 162 & 83 \\
Total protein & 38 & 20 & 66 & 34 \\
Thiamin & 72 & 37 & 102 & 52 \\
Ribofiavin & 79 & 41 & 121 & 62 \\
Calcium & 24 & 12 & 24 & 12 \\
Ascorbic acid & 23 & 12 & 105 & 54 \\
Iron & 128 & 66 & 176 & 90 \\
Cholecalciferol & 162 & 83 & 195 & 100 \\
Retinol & 90 & 46 & 90 & 46
\end{tabular}

because of the onset of hyperemesis. The disappointingly small number of immigrants studied (four) was mainly due to language barriers and in some instances was due to husbands refusing permission for their wives to co-operate. Those who did take part were either professionally trained in this country or married to postgraduate students.

\section{METHODS}

The aim was to obtain a complete weighed dietary intake for seven consecutive days, although a $5 \mathrm{~d}$ record was accepted if it included a weekend. At the initial interview with the dietitian each mother was provided with a record book in which to record food items, their weight and that of any uneaten food. She was loaned flat-topped scales graduated in divisions of one-sixth ounces $(4.7 \mathrm{~g})$ and weighing up to $32 \mathrm{oz}(907 \mathrm{~g})$. If more than one item of food was consumed from the same plate, the method of cumulative weighing was used, as this was considered to be reasonably quick and easy for the participant. This involved recording the weight of the plate and its subsequent weight as each item of food was added, and its weight with any uneaten food after the meal. Prescribed vitamin supplements have not been included as part of the dietary intake.

A minimum of two supervisory visits was made to each mother after the initial instruction. Problems were discussed and the dietitian had an opportunity to supplement descriptions of foods and of cooking methods. Where meals were eaten away from home and it was not possible to weigh them, the participant described them as accurately as possible and they were assessed by the dietitian.

A record was made of any previous or persisting nausea or vomiting in pregnancy. If vomiting occurred within $30 \mathrm{~min}$ of eating a meal, the whole meal was discounted. At the end of the recording period the books were coded by dietitians from a food code list supplied by the Department of Health and Social Security (DHSS) (unpublished results). The intakes were then transferred to 'punch' cards and analysed by computer (1906 A, International Computers Ltd, Bridge House, Putney Bridge, London SW6) using DHSS food composition tables (unpublished results). The computer print-out listed the average daily intake of the principal nutrients.

\section{RESULTS}

Nutrient intakes, observed and recommended

There are no British recommended dietary intakes specifically for the first trimester of pregnancy. We have therefore compared our observations with the intakes recommended 

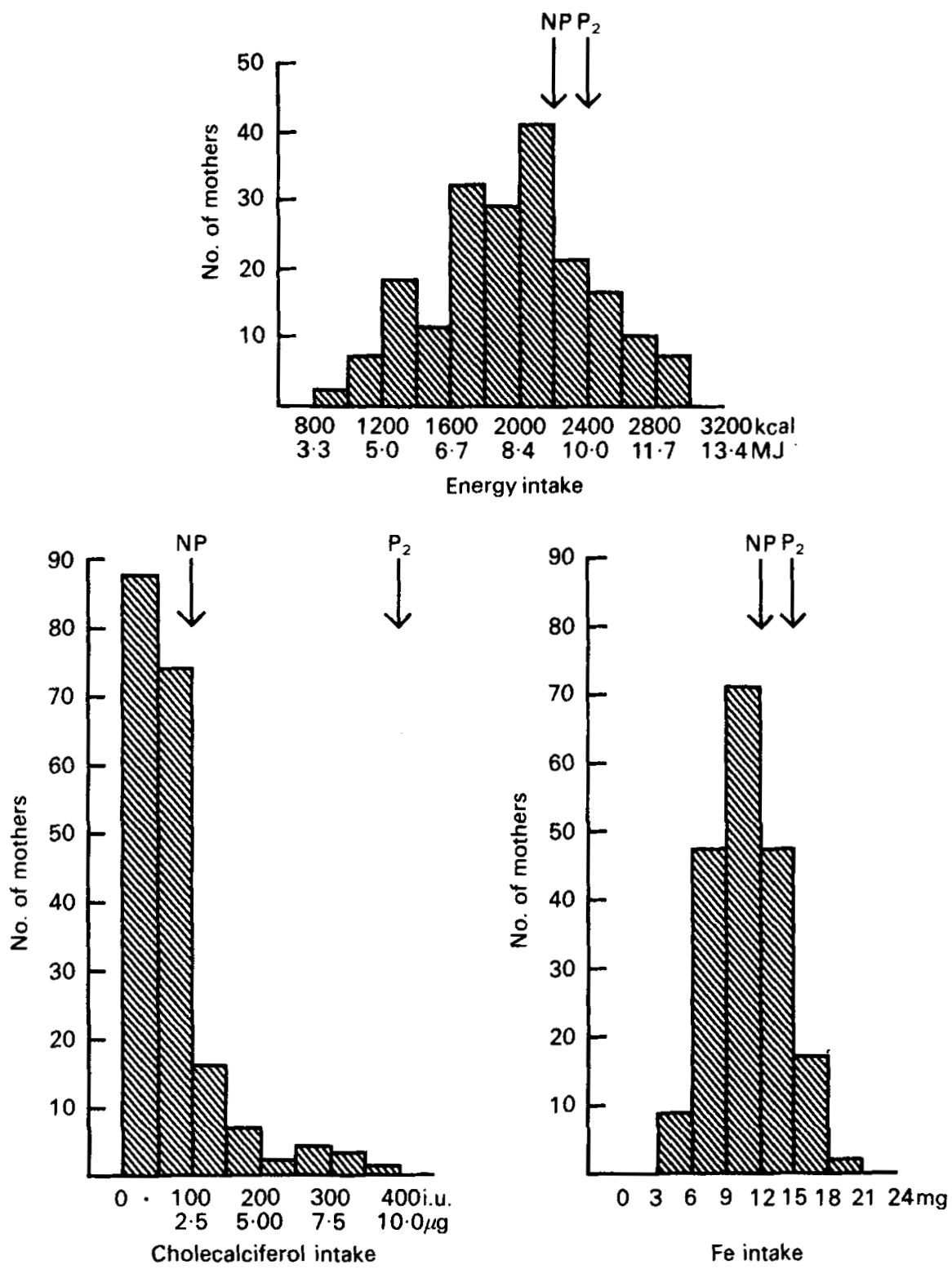

Fig. 1. Distribution of observed intakes of energy, cholecalciferol and Fe, for 195 women in the first trimester of pregnancy. NP and P2 recommended intakes for moderately-active non-pregnant women aged 18-55 and for women in the second trimester of pregnancy respectively (Department of Health and Social Security).

for moderately-active non-pregnant women aged 18-55 (RDI $\left.\mathrm{RP}_{\mathrm{NP}}\right)$ and for women in the second trimester of pregnancy ( $\mathrm{RDI}_{\mathrm{P} 2}$ ) (Department of Health and Social Security, 1969).

Table 1 indicates the relative numbers of mothers with intakes below the recommended values. It will be noted that the proportion of mothers having satisfactory intakes was very variable. If $\mathrm{RDI}_{\mathrm{NP}}$ are considered more than two-thirds of the mothers were having unsatisfactory energy, $\mathrm{Fe}$ and cholecalciferol intakes; one-third of the mothers were also 
having insufficient thiamin, riboflavin and retinol. Intakes of protein, $\mathrm{Ca}$ and ascorbic acid were more satisfactory. If comparison is made with $\mathrm{RDI}_{\mathrm{P2}}$, more than $80 \%$ of the mothers were receiving insufficient energy and $\mathrm{Fe}$, and all mothers had an unsatisfactory intake of cholecalciferol. The distribution of observed intakes of energy, $\mathrm{Fe}$ and cholecalciferol are shown in Fig. 1 on which are indicated $\mathrm{RDI}_{\mathrm{NP}}$ and $\mathrm{RDI}_{\mathrm{P2}}$. Comparisons between observed intake of nicotinic acid and $\mathrm{RDI}_{\mathrm{NP}}$ and $\mathrm{RDI}_{\mathrm{P} 2}$ could not be made because the former is expressed in $\mathrm{mg}$ and the latter in $\mathrm{mg}$ equivalents which include both the naturally occurring vitamin and that resulting from the conversion in the body of the amino acid tryptophan.

\section{Diets and social class}

Table 2 shows the mean values and standard deviations for the average daily intake of nutrients of the mothers, relative to their social class. As there were only eight mothers from social class $V$, this group has been combined with social class IV. There was a decreasing trend from social class $I$ to classes IV $+V$ in all components of the diet. However, mothers from class III manual (M) had lower intakes of energy, protein, carbohydrates and $\mathrm{Ca}$ than mothers in social classes IV $+\mathrm{V}$. When the social class differences are analysed by two-tailed $t$ tests, those between social classes I and II and between social classes III non-manual $(\mathrm{Nm})$ and IV $+\mathrm{V}$ are not significant; nor, with exception of $\mathrm{Ca}$, were those between social classes III M and III Nm.

For purposes of further analysis social classes $\mathrm{I}+\mathrm{II}$ and III $+\mathrm{IV}+\mathrm{V}$ were regarded as two social class groups. The difference in dietary intake between these two groups, shown in Table 3, was highly significant in favour of social class I+ II.

\section{Diets and maternal age}

It is widely believed that the diets of very young mothers are less satisfactory than those of older mothers. This possibility is explored in Table 4 in which the mean daily intakes of mothers under 20 years of age have been compared with those of older women. The younger mothers had significantly lower intakes of all nutrients. As twenty-six of the younger mothers were in social classes III + IV $+V$, Table 4 also compares the diets of younger and older mothers within this social class group. Apart from cholecalciferol the nutrient intakes of the younger mothers were again significantly lower than those of older mothers. However, the level of significance was generally less when comparison was made within social classes III + IV $+V$, suggesting that maternal age and social class contributed independently to dietary differences.

\section{Diets and smoking}

It might be anticipated that mothers who smoke would eat less than those who do not. Table 5 compares the mean daily nutrient intakes of mothers divided into four groups according to smoking habit in the first trimester. There was a tendency for the intake of most nutrients to be iower in mothers who smoked ten or more cigarettes daily than in those who smoked less or did not smoke at all. However, none of these differences was statistically significant.

\section{Diets and vomiting}

Vomiting during pregnancy inevitably renders impossible the accurate recording of dietary intake, and the information relating the two factors must be interpreted with caution. Of 195 mothers, eighteen had stopped vomiting shortly before starting their diet records and their intakes tended to be high. This probably represented 'catch-up' appetite and these mothers were excluded from the following analysis.

Table 6 analyses nutrient intake according to the presence or absence of nausea or vomiting at the time of the dietary survey. It will be noted that mothers experiencing 


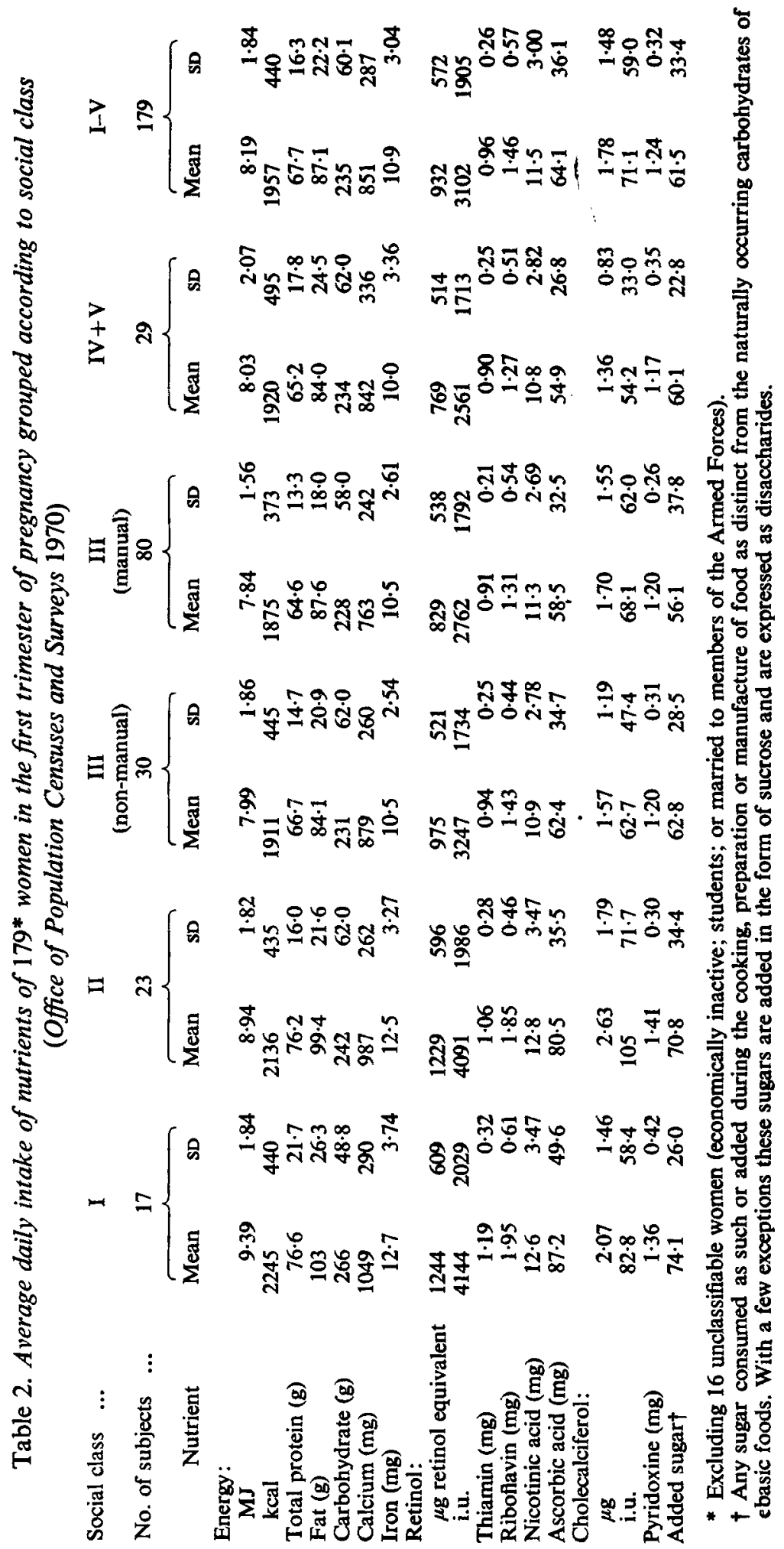


Table 3. Mean daily nutrient intakes of 179 women in the first trimester of pregnancy grouped according to social class (Office of Population Censuses and Surveys 1970) for social classes $I+I I$ compared with social classes $I I I+I V+V$

\begin{tabular}{|c|c|c|c|}
\hline $\begin{array}{c}\text { No. of subjects } \\
\text { Nutrient }\end{array}$ & I+II & $\mathbf{I I I}+\mathbf{I V}+\mathbf{V}$ & $\begin{array}{c}\text { Statistical } \\
\text { significance } \\
\text { of } \\
\text { difference: } \\
P\end{array}$ \\
\hline \multicolumn{4}{|l|}{ Energy: } \\
\hline $\begin{array}{l}\text { MJ } \\
\text { kcal }\end{array}$ & $\begin{array}{l}9 \cdot 13 \\
2183\end{array}$ & 1892 & $<0.001$ \\
\hline Protein (g) & $76 \cdot 4$ & 65.2 & $<0.001$ \\
\hline Fat $(\mathrm{g})$ & 101 & $83 \cdot 2$ & $<0.001$ \\
\hline Carbohydrate (g) & 252 & 230 & $<0.05$ \\
\hline Calcium (mg) & 1013 & 804 & $<0.001$ \\
\hline Iron (mg) & $12 \cdot 6$ & $10 \cdot 4$ & $<0.001$ \\
\hline \multicolumn{4}{|l|}{ Retinol: } \\
\hline $\begin{array}{l}\mu \mathrm{g} \text { retinol equivalent } \\
\text { i.u. }\end{array}$ & 1235 & 848 & $<0.001$ \\
\hline $\begin{array}{l}\text { i.u. } \\
\text { Thiamin (mg) }\end{array}$ & 4113 & 2825 & \\
\hline $\begin{array}{l}\text { Thiamin (mg) } \\
\text { Riboflavin (mg) }\end{array}$ & $1 \cdot 12$ & 0.91 & $\begin{array}{l}<0.001 \\
<0.001\end{array}$ \\
\hline Riboflavin (mg) & 1.89 & $1 \cdot 33$ & $<0,001$ \\
\hline Nicotinic acid (mg) & $12 \cdot 7$ & $11 \cdot 1$ & $<0.005$ \\
\hline Ascorbic acid (mg) & $83 \cdot 4$ & $58 \cdot 6$ & $<0.001$ \\
\hline \multicolumn{4}{|l|}{ Cholecalciferol: } \\
\hline $\begin{array}{l}\mu \mathrm{g} \\
\text { i.u. }\end{array}$ & $\begin{array}{l}2 \cdot 39 \\
95 \cdot 8\end{array}$ & $\begin{array}{l}1.60 \\
64 \cdot 0\end{array}$ & $<0.005$ \\
\hline Pyridoxine (mg) & 1.39 & $1 \cdot 19$ & $<0.001$ \\
\hline
\end{tabular}

Table 4. Mean daily nutrient intakes of 195 women in the first trimester of pregnancy grouped according to social class (Office of Population Censuses and Surveys 1970) and maternal age

Social class $\ldots$

No. of subjects $\ldots$ Nutrient

\section{Energy:}

$\mathrm{kcal}$

Protein (g)

Fat (g)

Carbohydrate (g)

Calcium (mg)

Iron (mg)

Retinol:

$\mu \mathrm{g}$ retinol equivalent i.u.

Thiamin (mg)

Riboflavin (mg)

Nicotinic acid (mg)

Ascorbic acid (mg)

Cholecalciferol:

$\mu \mathrm{g}$

i.u.

Pyridoxine (mg)
All mothers

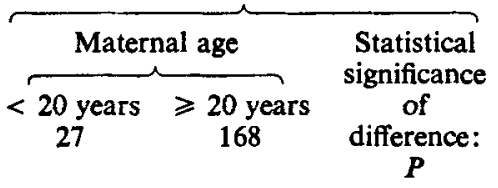

$\begin{array}{ccc}6.68 & 8.41 & <0.001 \\ 1596 & 2010 & \\ 53.7 & 69.8 & <0.001 \\ 68.6 & 90 \cdot 1 & <0.001 \\ 199 & 239 & <0.01 \\ 663 & 883 & <0.001 \\ 8.45 & 11.3 & <0.001\end{array}$

534
1781
$0 \cdot 74$
$1 \cdot 02$
$9 \cdot 23$
$41 \cdot 3$

$1 \cdot 19$

$47 \cdot 7$

1.00
$1000<0.001$

3332

$0.99<0.001$

$1.53<0.001$

$68.2<0.001$

$1.92<0.05$

$76 \cdot 7$

$1 \cdot 27$

$<0.001$

NS, not significant.
$11.80<0.001$

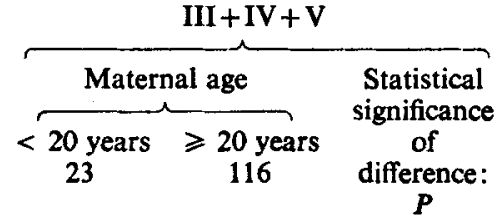

$\begin{array}{ccc}6.87 & 8.12 & <0.01 \\ 1641 & 1942 & \\ 54.5 & 67.3 & <0.001 \\ 70.3 & 85.8 & <0.001 \\ 205 & 235 & <0.05 \\ 689 & 827 & <0.05 \\ 8.64 & 10.7 & <0.001\end{array}$

$\begin{array}{ccc}551 & 908 & <0.01 \\ 1836 & 3022 & \\ 0.76 & 0.95 & <0.001 \\ 1.03 & 1.39 & <0.01 \\ 9.47 & 11.4 & <0.01 \\ 43.4 & 61.6 & <0.05\end{array}$

1.20

1.68

$67 \cdot 2$

NS

48.0
1.02

1.23

$<0.001$ 
Table 5. Mean daily nutrient intakes of 195 women in the first trimester of pregnancy grouped according to smoking habits

\begin{tabular}{|c|c|c|c|c|}
\hline No. of cigarettes smoked $/ \mathrm{d} \quad \ldots$ & None & $1-9$ & $10-19$ & $\geqslant 20$ \\
\hline No. of subjects $\ldots$ & 118 & 25 & 38 & 14 \\
\hline \multicolumn{5}{|l|}{ Nutrient } \\
\hline \multicolumn{5}{|l|}{ Energy: } \\
\hline MJ & 8.25 & $8 \cdot 55$ & 7.75 & $7 \cdot 97$ \\
\hline kcal & 1971 & 2043 & 1851 & 1904 \\
\hline Protein $(\mathrm{g})$ & 68.8 & $69 \cdot 6$ & $63 \cdot 6$ & 65.1 \\
\hline Fat (g) & 88.5 & $89 \cdot 2$ & 82.6 & 83.9 \\
\hline Carbohydrate (g) & 235 & 250 & 221 & 233 \\
\hline Calcium (mg) & 872 & 869 & 806 & 788 \\
\hline Iron (mg) & $11 \cdot 1$ & $11 \cdot 3$ & 10.0 & 10.6 \\
\hline \multicolumn{5}{|l|}{ Retinol: } \\
\hline$\mu \mathrm{g}$ retinol equivalent & 1017 & 845 & 850 & 655 \\
\hline i.u. & 3385 & 2813 & 2831 & 2182 \\
\hline Thiamin (mg) & 0.98 & 0.95 & 0.89 & 0.96 \\
\hline Riboflavin (mg) & $1 \cdot 50$ & 1.40 & $1 \cdot 40$ & $1 \cdot 36$ \\
\hline Nicotinic acid (mg) & 11.5 & 11.9 & $10 \cdot 8$ & 11.6 \\
\hline Ascorbic acid (mg) & 67.9 & $67 \cdot 4$ & $54 \cdot 1$ & $58 \cdot 1$ \\
\hline \multicolumn{5}{|l|}{ Cholecalciferol: } \\
\hline$\mu \mathrm{g}$ & 1.92 & 1.88 & 1.42 & 1.87 \\
\hline i.u. & 76.9 & $75 \cdot 2$ & $56 \cdot 8$ & $74 \cdot 8$ \\
\hline Pyridoxine (mg) & 1.24 & 1.32 & $1 \cdot 17$ & 1.19 \\
\hline
\end{tabular}

Table 6. Mean daily nutrient intakes of $177^{*}$ women in the first trimester of pregnancy grouped according to the incidence of vomiting during pregnancy

\begin{tabular}{|c|c|c|c|c|c|}
\hline Group no.† $\quad \ldots$ & 1 & 2 & 3 & 4 & Statistical \\
\hline No. of subjects $\ldots$ & 90 & 48 & 26 & 13 & $\begin{array}{l}\text { difference } \\
\text { between groups }\end{array}$ \\
\hline \multicolumn{5}{|l|}{ Nutrient } & 1 and $4: P$ \\
\hline \multicolumn{6}{|l|}{ Energy: } \\
\hline MJ & 8.33 & 8.54 & 7.55 & 6.58 & $<0.001$ \\
\hline kcal & 1992 & 2041 & 1804 & 1572 & \\
\hline Protein (g) & $67 \cdot 1$ & $73 \cdot 7$ & $63 \cdot 4$ & 53.9 & $<0.01$ \\
\hline Fat $(g)$ & 87.8 & 91.7 & $83 \cdot 2$ & 67.5 & $<0.001$ \\
\hline Carbohydrate (g) & 242 & 240 & 211 & 197 & $<0.05$ \\
\hline Calcium (mg) & 878 & 895 & 777 & 670 & $<0.05$ \\
\hline Iron (mg) & 10.9 & 11.9 & 9.89 & $8 \cdot 31$ & $<0.01$ \\
\hline \multicolumn{6}{|l|}{ Retinol: } \\
\hline$\mu \mathrm{g}$ retinol equivalent & 963 & 1024 & 797 & 667 & NS \\
\hline i.u. & 3208 & 3409 & 2655 & 2221 & \\
\hline Thiamin (mg) & 0.96 & 1.02 & 0.86 & 0.76 & $<0.01$ \\
\hline Riboflavin (mg) & $1 \cdot 51$ & 1.55 & $1 \cdot 30$ & 1.02 & $<0.01$ \\
\hline Nicotinic acid (mg) & $11 \cdot 3$ & 12.4 & 10.8 & 8.59 & $<0.001$ \\
\hline Ascorbic acid (mg) & 67.9 & $70 \cdot 6$ & $52 \cdot 3$ & $45 \cdot 2$ & $<0.05$ \\
\hline \multicolumn{6}{|l|}{ Cholecalciferol: } \\
\hline$\mu \mathrm{g}$ & 1.63 & $2 \cdot 10$ & 1.89 & $1 \cdot 17$ & NS \\
\hline i.u. & $65 \cdot 3$ & $84 \cdot 2$ & 75.7 & $46 \cdot 8$ & \\
\hline Pyridoxine (mg) & 1.23 & 1.35 & $1 \cdot 17$ & 0.85 & $<0.001$ \\
\hline
\end{tabular}


nausea but no vomiting had rather higher intakes of most nutrients, but the differences were not significant. The intakes of 'vomiting' mothers were lower, especially in those with more severe vomiting. The deficit of intake by mothers with mild vomiting was not significant for most nutrients. Mothers with more severe vomiting had reduced intakes of all nutrients and with the exception of retinol and cholecalciferol, the differences were statistically significant.

Of the twenty-eight mothers aged less than 20 years only three were vomiting at the time of the survey and none had severe vomiting. The lower nutrient intake of young mothers cannot therefore be attributed to pregnancy sickness.

\section{Dietary intake and blood concentration}

Mean daily intakes of ascorbic acid, riboflavin and Fe were compared with the concentrations of leucocyte ascorbic acid, erythrocyte riboflavin and haemoglobin assayed on blood samples collected at the time of dietary assessment. The coefficients of correlation obtained were: ascorbic acid: $0.18, P<0.05$; riboflavin: $-0.22, P<0.01$ (erythrocyte riboflavin was assessed as a saturation ratio (Glatzle, Korner, Christeller \& Wiss, 1970): the correlation has a negative value because increasing values represented decreasing riboflavin status); Fe: 0.075 , not significant.

A similar analysis for folate was not possible because food folate values were not available when the study was undertaken.

\section{DISCUSSION}

\section{Limitations of method}

Dietary surveys done during the first trimester have various inherent problems. Many women do not report to the doctor until they are more than 12 weeks pregnant and this is especially true of women whose nutrition probably deserves the closest scrutiny. This delay and an inability to communicate accounted for the small numbers of immigrant volunteers. The ability to write and to count is a prerequisite for the maintenance of a weighed dietary record and we suspect that failure to acquire these skills may partly explain the reluctance of some mothers from social class $\mathrm{V}$ to participate. The aim of our study was to reflect dietary patterns during the first few weeks of pregnancy, but as soon as pregnancy is confirmed women frequently alter their eating habits, one example being an increase in the consumption of milk. Nausea and vomiting influence intake and may also render a mother unwilling to complete a dietary record. Any allowances made for vomiting will inevitably be somewhat arbitrary.

Neither the ' $24 \mathrm{~h}$-recall' method nor the ' $7 \mathrm{~d}$ food diary' is wholly dependable in the assessment of dietary intake (Burke, 1947; Bransby, Daubney \& King, 1948). For example, when Brown, Rogers \& Pang (1975) investigated the dietary intake of young women of child-bearing age they rejected 113 of 2004 -d records because participants had failed either to record for four consecutive days or to describe portion sizes accurately. In comparison we rejected only four of 199 records. However, this high acceptance rate was obtained at the cost of many 'dietitian hours'. In an attempt to obtain a reasonably accurate record of dietary intake, two full-time dietitians were engaged in the study for 15 months and conducted some 200 initial interviews and over 400 supervisory visits.

An alternative method for the assessment of maternal nutritional status has been proposed by Rush (1975), by which measurements of both fat-pad thickness and weight gain would be used to estimate energy balance in pregnancy. However, information about intakes of specific nutrients would not be achieved by this technique. 


\section{Dietary intake}

In comparison with $\mathrm{RDI}_{\mathrm{NP}}$, those of many of the mothers studied were low. These findings are in keeping with the Australian study of Brown et al. (1975). The relative number of their volunteers taking less than the recommended allowances ( $\%$ total volunteers) were Fe 74, thiamin 25, Ca 14, ascorbic acid 7 .

The majority of mothers in the present study were nearing the end of the first trimester of pregnancy and, it might be argued, should ideally have had intakes approaching those suggested for the second trimester, in which situation the results obtained are more disturbing. In no instance did a mother have a cholecalciferol intake of $10 \mu \mathrm{g}$ (400 i.u.) which is the recommendation throughout pregnancy and is based on the possible requirements of women in whom there may be inadequate exposure to sunlight.

The decreasing trend in nutrient intakes of mothers from social class I to classes IV $+\mathrm{V}$ parallels our findings in a larger group of pregnant women in whom we determined levels of erythrocyte and serum folate, leucocyte ascorbic acid, serum retinol and erythrocyte riboflavin (Smithells et al. 1976).

When comparisons are made by age, younger mothers had lower mean intakes of all nutrients than had older mothers. These results are in accord with the conclusions reached in Weighley's (1975) recent review of nutritional research in the USA that suboptimal food intake is common in pregnant adolescents.

However, Morse and her co-workers (Morse, Clarke, Merrow \& Thibault, 1975) found that dietary intakes of pregnant adolescents were lower than those of older women only in a few specific nutrients (retinol, ascorbic acid, thiamin and niacin).

Examination of the dietary records of our twenty-seven young mothers showed frequent use of convenience foods. Only four mothers prepared and cooked a meal each day and four others did so only on Sunday. Few ate fresh fruit or vegetables and in some records the only source of ascorbic acid was chipped potatoes, which together with fried fish, potato crisps and sandwiches formed a major part of the diet.

It is not surprising that mothers who were experiencing quite severe vomiting proved to have nutrient intakes significantly lower than those of mothers who did not vomit. The differences cannot be attributed either to our decision to discount any meal vomited within $30 \mathrm{~min}$ of ingestion as only two deletions were noted in the records of the thirteen mothers who experienced severe vomiting, or to a social class distribution differing significantly from that of all mothers. Mothers suffering from nausea without vomiting had the highest intake of all nutrients, except carbohydrate. Their diet books showed that many of them had a late breakfast which was quite substantial and usually included an egg.

It is generally accepted that babies born to mothers who smoke heavily in pregnancy are lighter-for-dates than are those born to non-smokers (Butler \& Alberman, 1969). Butler, Goldstein \& Ross (1972) reported that smoking habits established at the end of the 4th month of pregnancy appeared to have most effect on its outcome. Mothers who smoked more than ten cigarettes/d had lower mean intakes of most nutrients than had non-smokers, but we do not know whether dietary and smoking patterns obtained in the first trimester continued unchanged throughout the pregnancy.

The correlations between dietary intakes and biochemical concentrations, even where significant, showed weak associations. On consideration this is not surprising as the assessments of leucocyte ascorbic acid and erythrocyte riboflavin reflect body stores rather than current intake (Bessey, Horwitt \& Love, 1956; Andrews \& Brooks, 1968; Sauberlich, 1975). In the correlation analysis we assumed a linear relationship between dietary intake and cellular levels. However, it has been shown that an increase in dietary ascorbic acid does not lead to a proportional increase in leucocyte levels (Wilson, 1975). Indeed as 
leucocyte levels approach saturation, even pharmacological doses of ascorbic acid cause little change. Similarly, when $\mathrm{Fe}$ is given to combat anaemia, absorption decreases as the haemoglobin levels approach normal values.

We are aware that recommended intakes of nutrients should not be equated with requirements. Nevertheless, our results indicate that young women from social classes III, IV and $\mathrm{V}$ may be at nutritional risk. Our results are supported by the biochemical findings demonstrating that these social classes have poorer vitamin reserves (Smithells et al. 1976). There is clearly a need for pre-conceptional dietary counselling and as those at greatest risk are the young, then the final school year could well be the optimal time for such education.

The authors thank the mothers who volunteered for the study; the doctors who assisted in it, in particular Drs Ann Meynell, Margaret Plowman and Beryl Stevenson; Mr Peter Zemroch for preparation of the computer programmes and analysis of the results, and Action for the Crippled Child for their generosity. This study was made possible by the financial support of the Department of Health and Social Security (C.A. and D.L.) and by their help and advice which is acknowledged with gratitude.

\section{REFERENCES}

Andrews, J. \& Brooks, M. (1968). Geront, clin. 10, 128.

Bessey, O. A., Horwitt, M. K. \& Love, R. H. (1956). J. Nutr. 58, 367.

Bransby, E. R., Daubney, C. G. \& King, J. (1948). Br. J. Nutr. $2,89$.

Brown, B., Rogers, J. F. \& Pang, M. (1975). Med. J. Aust. 2, 785.

Burke, B. S. (1947). J. Am. diet. Ass. 23, 1041.

Butler, N. R. \& Alberman, E. D. (1969). Perinatal Problems. Edinburgh \& London: E. \& S. Livingstone.

Butler, N. R. \& Bonham, D. G. (1963). Perinatal Mortality. Edinburgh \& London: E. \& S. Livingstone.

Butler, N. R., Goldstein, H. \& Ross, E. M. (1972). Br. Med. J. ii, 127.

Department of Health and Social Security. (1969). Rep. Publ. Hlth med. Subj., Lond. no. 120.

Glatzle, D., Korner, W. F., Christeller, S. \& Wiss, O. (1970). Int. Z. VitamForsch. 40, 166.

Morse, E. H., Clarke, R. P., Merrow, S. B. \& Thibault, B. E. (1975). Am. J. clin. Nutr. 28, 1422.

Office of Population Censuses and Surveys. (1970). Classification of Occupations. London: H.M. Stationery Office.

Office of Population Censuses and Surveys. (1973). General Household Survey. London: H.M. Stationery Office.

Rush, D. (1975). Am. J. Dis. Child. 129, 430.

Smithells, R. W., Sheppard, S. \& Schorah, C. J. (1976). Archs. Dis. Childh. 51, 944.

Sauberlich, H. E. (1975). Ann. N.Y. Acad. Sci. 258, 438.

Weighley, E. J. (1975). J. Am. diet. Ass. 66, 588.

Wilson, C. W. M. (1975). Ann. N.Y. Acad. Sci. 258, 355. 